\title{
Rancangan Sistem Mounting Device Berbasis PLC Menggunakan HMI
}

\author{
Tito Ardiansyah ${ }^{1}$, dan Risfendra ${ }^{2}$ \\ 1,2 Universitas Negeri Padang \\ Jl. Prof Dr. Hamka Air Tawar, Padang, Indonesia \\ Titoardiansyah09@gmail.com ${ }^{1}$,risfendra@ft.unp.ac.id ${ }^{2}$
}

\begin{abstract}
In general, the development of modern technology and automation in the industrialized world currently many make work just got easier. Especially industry in Indonesia currently it has progressed which is very significant. Many industries have started to leave manual systems and have switched to more modern automation systems and technology. Another problem that arises from manual systems is that industries that still use manual systems or still require human labor cannot meet company targets optimally. So the industry is now required to produce products quickly in order to meet consumer demand, with quality and industrial processes according to company standards and achieve maximum targets. An alternative that can be done is to see the problems that are still many in the industry today, namely the construction of a production process that uses an automatic system. From this industrial demand, a modern automation control system using PLC was developed. Where currently PLC is very much used as the main automation control in an industry. In addition, it also cooperates with PLC and HMI. One of the main functions of HMI is to connect humans to technology and improve the interaction between machines and operators through screen displays. HMI itself functions to display machine errors, system processes, current system status and perform maintenance on machine performance. To anticipate all of that, this mounting device system is designed to use a PLC as a control and uses HMI to monitor the state of the device which is controlled by the SIEMENS Type S7 300 PLC and is displayed on the HMI using the TIA Portal software version 13. With this tool, at least it can improve mastery and ability to use PLC as a control system and be able to use HMI as a monitoring tool. Also able to master the program by using the TIA Portal v 13 Software..
\end{abstract}

Keywords- PLC SIEMENS S7 300; HMI Tipe 700 Comfort; PC; TIA Portal V 13.

Abstrak - Pada umumnya perkembangan teknologi modern dan otomatisasi didunia industri saat ini banyak membuat pekerjaan menjadi lebih mudah. Terutama industri di indonesia saat ini sudah mengalami kemajuan yang sangat signifikan. Banyak industri yang mulai meninggalkan sistem manual dan sudah beralih ke sistem otomasi dan teknologi yang lebih modern. Masalah lain yang timbul dari sistem manual adalah industri yang masih menggunakan sistem manual atau masih membutuhkan tenaga manusia tidak bisa memenuhi target perusahaan secara optimal. Maka industri sekarang dituntut untuk menghasilkan produk secara cepat agar dapat memenuhi permintaan konsumen, dengan kualitas dan proses industri sesuai standard perusahaan dan mencapai target yang lebih maksimal. Alternatif yang dapat dilakukan melihat masalah yang masih banyak di industri saat ini, yaitu dengan dibangunnya proses produksi yang menggunakan sistem otomatis. Dari tuntutan industri seperti ini maka dikembangkan suatu sistem kontrol otomasi modern menggunakan PLC. Dimana saat sekarang ini PLC sangat banyak dijadikan sebagai kontrol otomasi utama dalam sebuah industri. Selain itu juga menggandengkan PLC dengan HMI. Salah satu fungsi utama HMI untuk menghubungkan manusia dengan teknologi dan meningkatkan nteraksi antara mesin dengan operator melalui tampilan layar. HMI sendiri berfungsi untuk menampilkan kesalahan mesin, proses sistem, status sistem yang sedang berjalan dan melakukan maintenance terhadap kinerja mesin. Untuk mengantisipasi semua itu, sistem mounting device ini didesain menggunakan PLC sebagai kontrol dan menggunakan HMI untuk memonitoring keadaan alat yang dikontrol semua oleh PLC SIEMENS Type S7 300 dan ditampilkan di HMI menggunakan software TIA Portal versi 13. Dengan adanya alat ini, setidaknya dapat meningkatkan penguasaan dan kemampuan menggunakan PLC sebagai sistem kontrol dan mampu menggunakan HMI sebagai monitoring alat. Juga dapat menguasai program dengan menggunakan Software TIA Portal v 13.

Kata kunci- PLC SIEMENS S7 300; HMI Tipe 700 Comfort; PC; TIA Portal V 13.

\section{Pendahuluan}

Di zaman maju dan berkembang ini, telah banyak hal yang diubah menjadi sebuah sistem otomatis yang dapat memudahkan pekerjaan manusia, kemajuan teknologi yang mempuni, membuat sistem produksi di indonesia sangat meningkat. Salah satu alat otomasi yang banyak digunakan di era modern saat ini yaitu PLC dan HMI. PLC dan HMI sangat banyak digunakan diindustri industri besar saat ini [1]. Salah satu keunggulan PLC yaitu dapat mengontrol mesin industri dengan mudah dan terstruktur. Sedangkan HMI saat ini banyak digunakan sebagai media monitoring sistem yang ada di industri. HMI sendiri digunakan untuk mengetahui kesalahan pada mesin, proses kerja mesin serta dapat melakukan pengawasan dan maintenance terhadap mesin di industri. Dengan adanya PLC dan HMI dapat memudahkan seluruh kinerja pada mesin - mesin yang ada di industri - industri besar [2].

Khususnya pada bidang Otomasi masih sedikit kajiankajian mendalam mengenai PLC. Maka dari itu dengan 
penerapan pada rancang bangun alat ini menggunakan PLC, diharapkan adanya peningkatan kualitas dalam penguasaan dengan menggunakan PLC sebagai sistem kontrol. Sedangkan untuk HMI adalah sistem yang menghubungkan manusia dengan teknologi mesin. Tujuan dari HMI adalah meningkatkan interaksi antara mesin dengan operator melalui tampilan layar/display [3].

Untuk mengatasi permasalahan pada sistem manual yang dulu banyak di gunakan di industri, pada sistem Mounting device kali ini dapat mempelajari bagaimana mengontrol dan menggunakan PLC serta HMI. Sistem Mounting device ini dirancang secara lebih otomatis menggunakan Software TIA Portal. PLC sebagai unit kontrol yang dgunakan yaitu PLC Merk SIEMENS dan menggunakan HMI Tipe Comfort. HMI sebagai monitoring keadaan alat Mounting Device berguna untuk mengetahui apabila ada kesalahan atau gangguan pada alat ini [4].

Sistem Mounting Device adalah proses pengemasan tutup botol/kaleng secara otomatis. Software TIA Portal sebagai program penunjang bekerja nya alat ini. Alat ini dirancang khusus agar bisa menguasai PLC sebagai unit kontrol dan HMI sebagai unit monitoring [5].

Alat ini dibuat berupa rancangan sistem pengontrolan dan pemograman. Kontroller yang digunakan adalah PLC merek SIEMENS tipe S7-300 dengan Modul Interface dengan menggunakan SIMATIC HMI TP 700 comfort. Monitoring dan pengontrolan dengan menggunakan HMI TP 700 comfort. Serta Software yang digunakan TIA PORTAL v.13 untuk merancang Ladder Diagram dan tampilan HMI (Human Machine Interface) [6].

Power Supply merupakan suatu bagian terpenting dari suatu rangkaian elektronika, dan juga suatu sumber tegangan penggerak dari rangkaian elektronika. Power supply berasal dari sumber tegangan jala-jala PLN dengan arus AC, sedangkan pada keluarannya telah menjadi arus DC.

Driver Motor berfungsi untuk mengendalikan pergerakan Motor DC yang akan menggerakan konveyor. Solenoid Valve berfungsi untuk mengatur pergerakan silinder Pneumatic .

PC (Komputer/laptop) adalah alat yang dipakai untuk mengolah data menurut prosedur yang telah dirumuskan. PC digunakan sebagai perangkat untuk memprogram PLC dan HMI.

HMI penggunaannya bisa sebagai input dan output. Sebagai input bisa mengatur parameter pada sistem dan sebagai output bisa melakukan monitoring pada sistem.

Ethernet PN/IE digunakan sebagai kabel untuk komunikasi PC-PLC-HMI. Sistem ini memiliki dua mode operasi yaitu manual dan otomatis. Mode manual dikendalikan dengan menekan tombol virtual yang ada pada HMI. Mode otomatis berjalan dengan bantuan sensorsensor yang mendeteksi keberadaan pallet.

Software TIA Portal merupakan salah satu alat bantu untuk membuat berbagai macam program komputer, khususnya yang menggunakan sistem operasi PLC.
Software TIA Portal merupakan salah satu pemograman dengan Ladder Diagram [7].

Diagram Alir (Flowchart) adalah penggambaran secara grafik dari langkah-langkah dan urutan prosedur dari suatu program.

\section{Metode}

Pada bab ini akan membahas tentang perancangan hardware dan software.

\section{A. Blok Diagram}

Blok diagram merupakan pendefinisian terhadap sistem yang dirancang yang bersifat menyeluruh seperti terdapat pada Gambar 1.

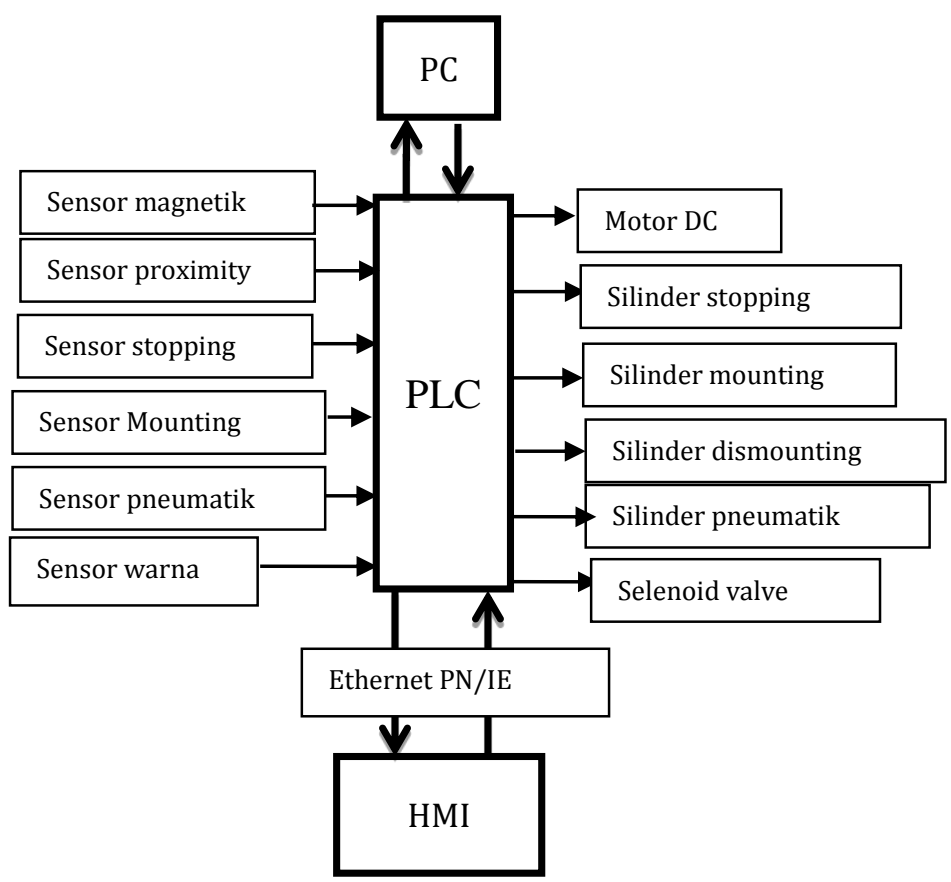

Gambar 1. Blok Diagram Sistem

Di bawah ini akan dijelaskan fungsi dari masing-masing blok perancangan alat di atas:

1. PLC

Blok ini berfungsi sebagai pusat pengontrolan kendali sesuai dengan input yang diberikan. Semua input akan disimpan dan diproses sesuai dengan program yang digunakan yaitu software TIA Portal.

2. Power supply

Unit power supply / catu daya sebagai sumber utama dari semua rangkaian pada sistem.

3. HMI penggunaannya bisa sebagai input dan output. Sebagai input bisa mengatur parameter pada sistem dan sebagai output bisa melakukan monitoring pada sistem.

4. Ethernet PN/IE digunakan sebagai kabel untuk komunikasi PC-PLC-HMI.

5. PC digunakan sebagai perangkat untuk memprogram PLC dan HMI. 
6. Sensor Magnetik berfungsi mendeteksi pallet saat berada dikonveyor.

7. Sensor Proximity berfungsi untuk mendeteksi pergerakan piston yang ada pada silinder Pneumatic sehingga Pneumatic dapat beroperasi.

8. Sensor Stopping berfungsi untuk mendeteksi pergerakan pallet yang melewati sensor proximity.

9. Sensor pneumatic berfungsi ketika saat membuka tutup kaleng pada pallet, slinder pneumatic akan menerima perintah untuk membuka tutup kaleng.

\section{B. Perancangan Mekanik}

Pada perancangan mekanik alat, akan membahas tentang desain sketsa alat baik dalam bentuk hardware maupun software.

\section{Perancangan Hardware}

Perancangan hardware merupakan tahapan dalam pembuatan suatu objek nyata dari sebuah alat. Perancangan Hardware bertujuan untuk memudahkan serta mengurangi tingkat kesalahan dalam pembuatan alat. Untuk bentuk hardware pada alat ini akan terlihat seperti pada gambar dibawah ini:

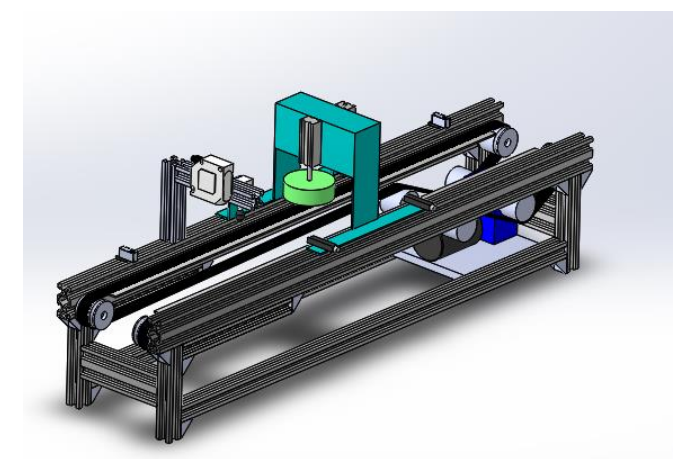

\section{Gambar 2. Sketsa alat secara keseluruhan}

Untuk keperluan pemograman PLC dan HMI, PC dihubungkan ke PLC dengan mengunakan kabel ethernet RJ-45 (LAN), seperti pada Gambar 3 Untuk pemograman HMI komunikasi HMI-PC melalui perantara PLC melalui konektor yang terdapat pada PLC. Koneksi antara PLC dan HMI juga menggunakan kabel ethernet RJ-45, seperti pada Gambar 3:

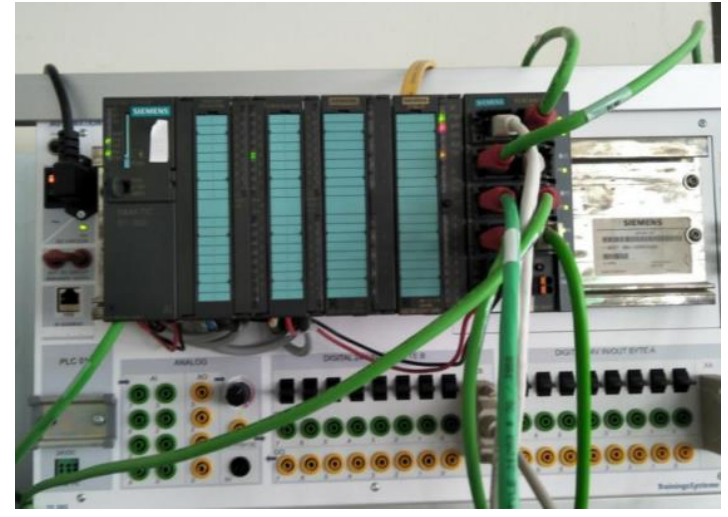

Gambar 3. Koneksi ke PLC

\section{Perancangan Software}

Pada perancangan software berguna untuk mendukung dalam kelancaran kerja dalam dari perangkat mekanik . Pada bagian ini akan menjelaskan tentang perancangan HMI seperti yang diperlhatkan pada gambar 4 dibawah ini :

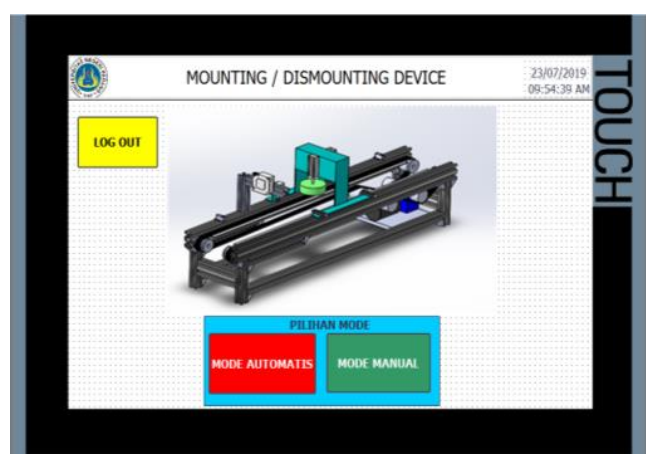

Gambar 4. Halaman HOME HMI

Pada perancangan pemograman HMI terdapat tampilan screen yaitu Log out, Mode Automatis dan Mode Manual.

a. Tombol log out, memiliki fungsi untuk mengembalikan ke posisi sebelumnya yaitu system screen.

b. Mode Automatis terdapat tombol Button yang mana apabila ditekan maka akan berpindah ke halaman Automatis .

c. Mode Manual terdapat juga tombol Button yang mana apabila ditekan maka akan berpindah ke halaman Mode Manual.

\section{Pengawatan pada Input dan Output PLC}

Pengawatan input dan output PLC digunakan untuk pengontrolan sistem Mounting dan Dismounting. Untuk pengalamatan dapat dilihat pada Gambar 5. 


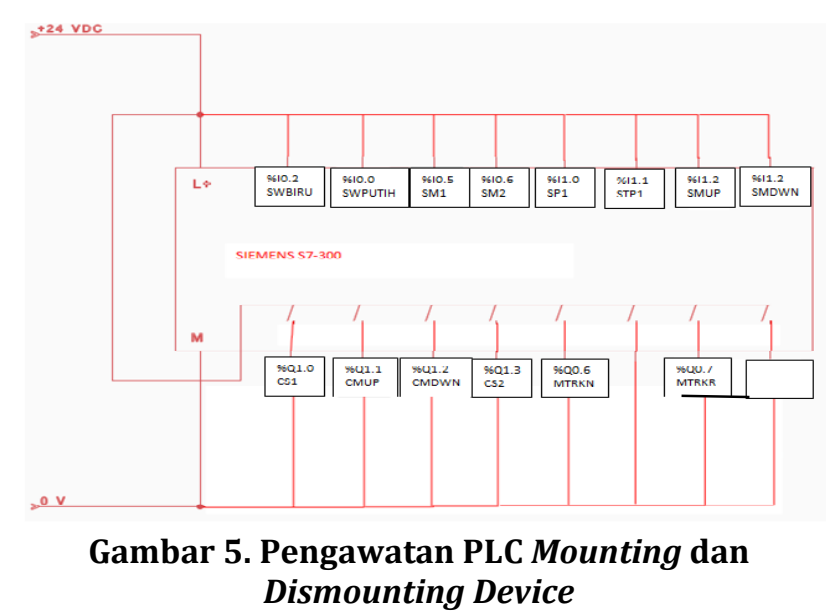

Berikut ini flowchart saat mode Mounting yang dapat dilihat pada Gambar 6 dan flowchart saat Dismounting yang terdapat pada Gambar 7.

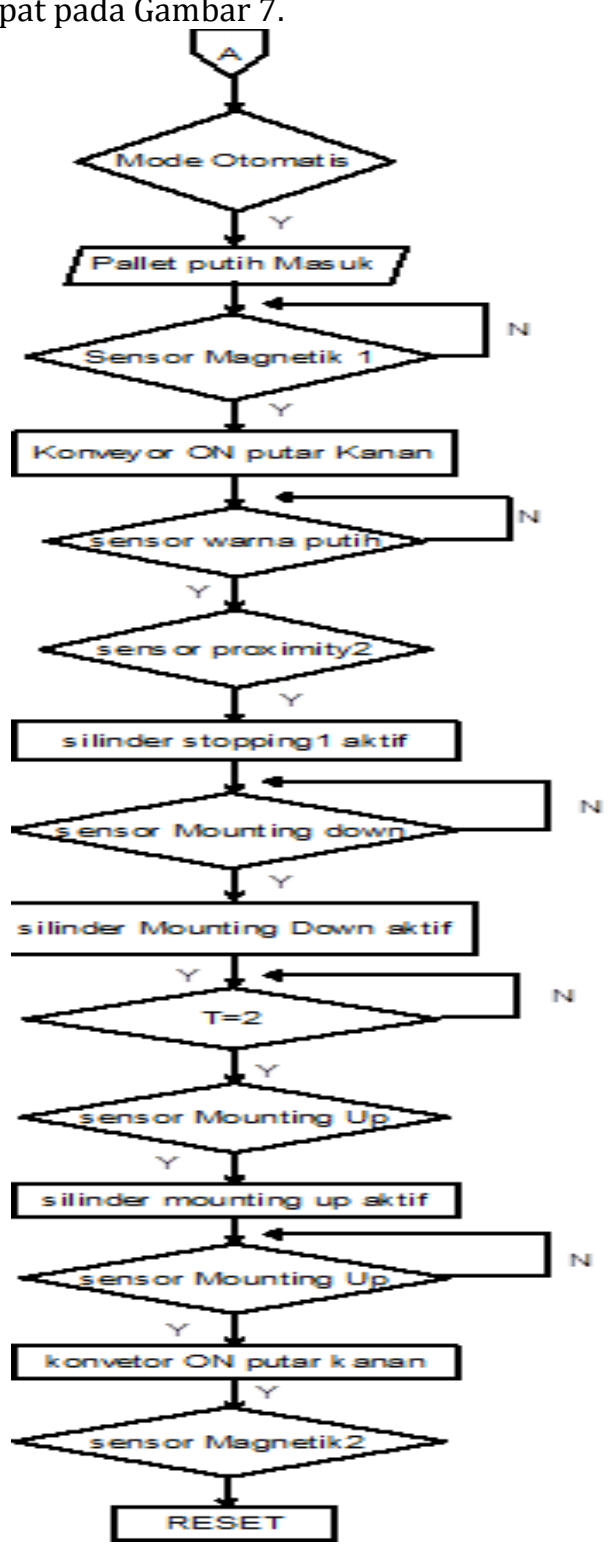

Gambar 6. Flowchart Mounting

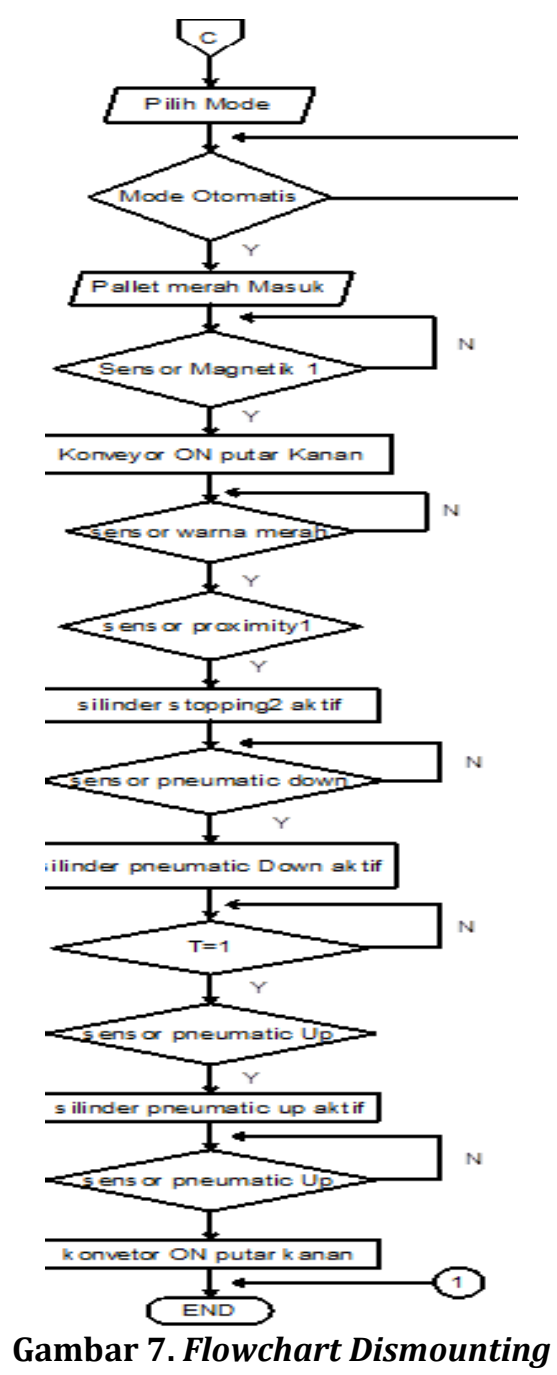

Prinsip kerja pada sistem Mounting (Gambar 6) yaitu pada saat mode automatis dipilih, pallet diposisikan diatas konveyor. Saat pallet membawa tutup kaleng berwarna (biru/putih), sensor magnetic akan mendeteksi pallet untuk menggerakan konveyor, sehingga konveyor bergerak ke arah kanan. Jika tidak terdeteksi konveyor tidak akan bergerak.

Saat sensor proximity mendeteksi pergerakan pallet, silinder stopping akan menahan [ergerakan pallet. Pada saat pallet berhenti dalam dengan hitungan timer sensor mounting menerima sinyak untuk aktif, dan tutup kaleng pun akan terpasang.

Dalam hitungan timer yang telah disetting sesuai kebutuhan, secara automatis akan mengaktifkan sensor mounting untuk menggerakan konveyor. Sehingga konveyor bergerak ke kanan menuju sensor magnetic sinyal untuk aktif maka proses Mounting telah aktif.

Prinsip kerja pada sistem Dismounting (Gambar 7) yaitu pada saat mode automatis dipilih, pallet diposisikan diatas konveyor. Saat pallet membawa tutup kaleng berwarna (merah) sensor magnetic akan mendeteksi pallet untuk menggerakan konveyor, sehingga konveyor bergerak ke 
arah kanan. Jika tidak terdeteksi konveyor tidak akan bergerak.

Ketika Sensor Warna Merah menerima sinyal untuk aktif maka Sistem Dismounting akan aktif. Saat Sensor Proximity mendeteksi pergerakan pallet, Silinder Stopping aktif dan menahan pergerakan pallet. Saat Sensor Pneumatic Down aktif mendeteksi pergerakan pallet, Silinder Pneumatic Down aktif dan membuka tutup kaleng.

Setelah itu Timer akan aktif dan menghitung selama 1 detik serta memicu Sensor Pneumatic Up atau untuk aktif. Timer aktif selama 1 detik setelah itu Silinder Pneumatic Up akan aktif dan bergerak keatas untuk melepas pemasangan tutup kaleng tersebut. Saat bersamaan Sensor Pneumatic Up akan memicu untuk aktif sehingga motor bergerak secara otomatis dan konveyor bergerah kearah kanan atau CW.

\section{PEngujian DAN ANALISIS DATA}

Suatu peralatan atau program dapat dikatakan bekerja dengan baik jika telah dilakukan pengujian sesuai fungsi kerja dari alat tersebut. Pengujian dimaksudkan untuk mendapatkan evaluasi terhadap sistem yang telah dikerjakan agar menghasilkan kinerja yang lebih baik dengan melakukan perbaikan terhadap rangkaian yang mengalami kekurangan saat pengujian. Tujuannya untuk melihat sejauh mana alat yang dibuat penulis apakah bekerja secara baik atau tidak.

Tabel 1. Pengujian pada Sistem Mounting Device

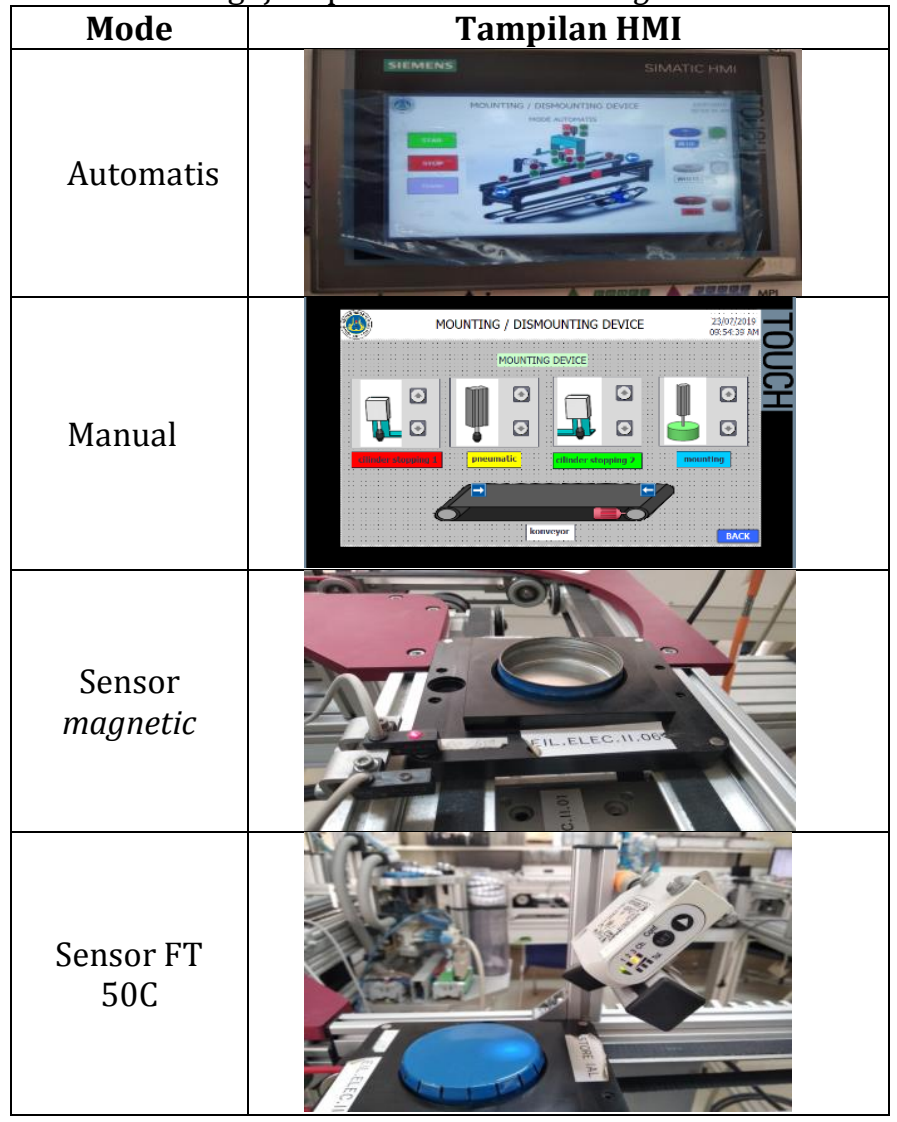

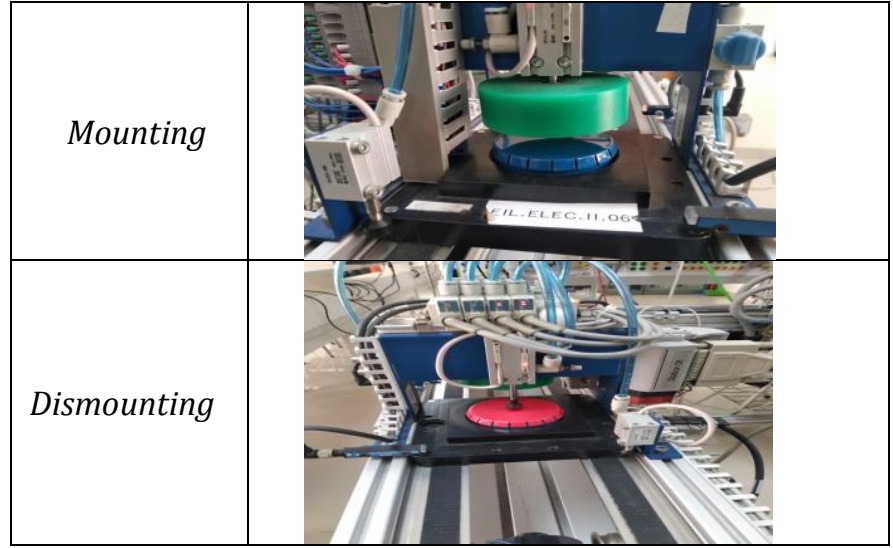

Tabel 1 memperlihatkan bentuk nyata dari sistem Mounting device. Pada mode Automatis dijelaskan dengan tampilan HMI. Sistem kerja mode Automatis di tandai dengan visual $L E D$ yang akan memberi tanda berkedip jika beroperasi. Untuk mode Manual pada HMI ditandai dengan Visual push button. Dimana mode manual akan aktif ketika salah satu button ditekan.

Tabel 2. Ladder Diagram Sistem Mounting Device

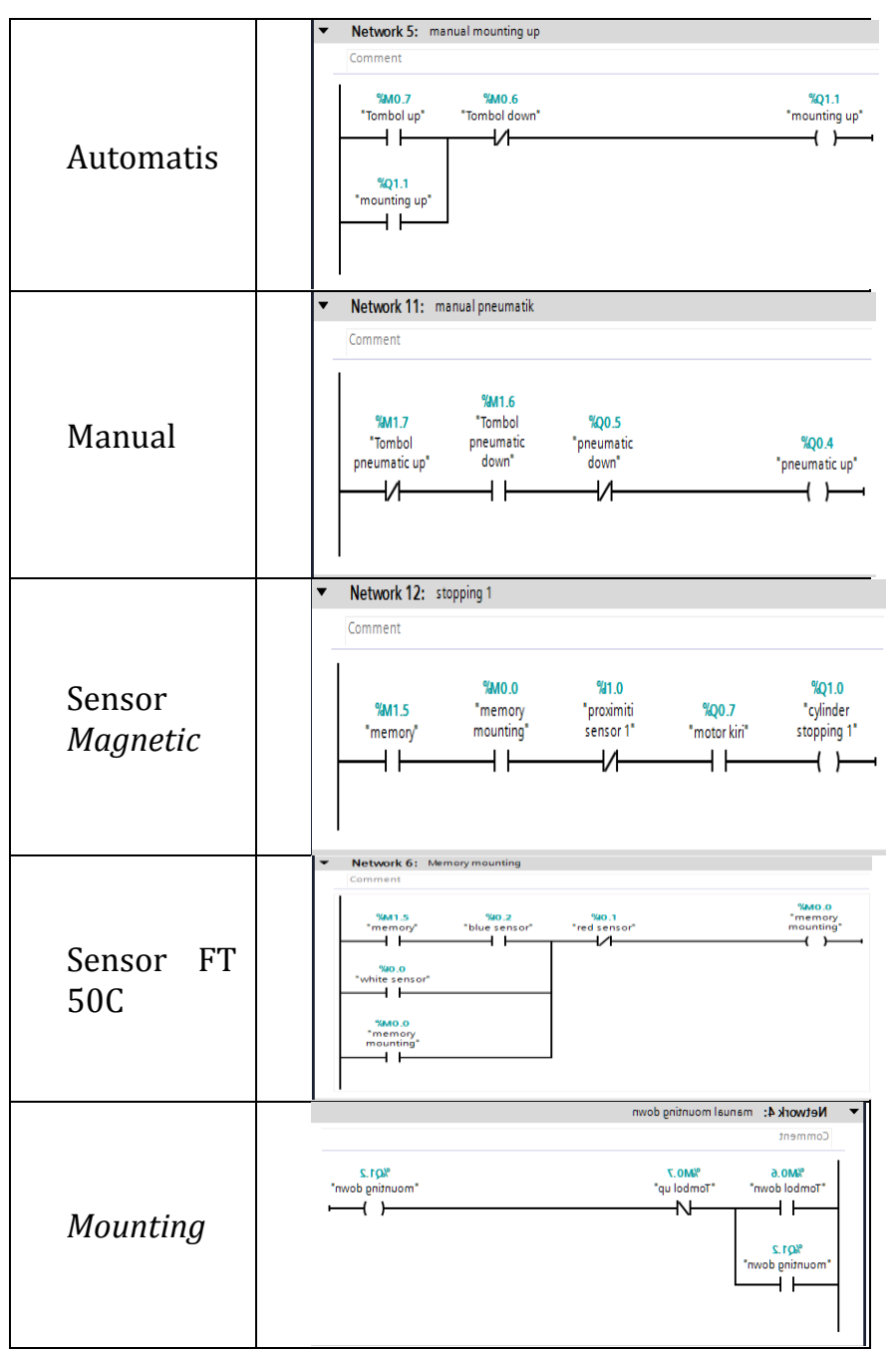




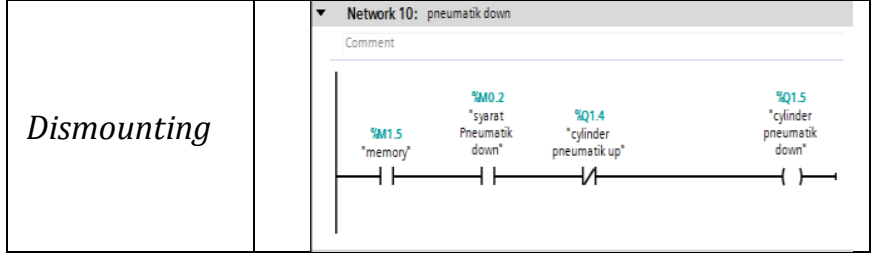

Pada hasil pengujian kali ini sistem Mounting device bekerja dengan sangat baik. Dalam proses pemograman, pengontrolan dengan PLC serta desain HMI dapat beroperasi secara terstruktur. Pengujian dimulai dengan cara memprogram alat membuat ladder diagram, diteruskan dengan membuat desain HMI serta mengoperasikan alat. Tujuan pengujian alat ini yaitu untuk mengetahui bagaimana sistem kerj a rancangan Mounting device secara otomatis serta bagaimana cara memonitoring/menganalisa rangkaian apabila terjadi kesalahan program.

Untuk menguji alat ini sangat dibutuhkan ketelitian khusunya dalam memprogram, mendesain HMI sesuai dengan kebutuhan serta dibutuhkan pemahaman untuk mengetahui apabila terjadi trouble seperti salah satu sensor yang tidak terbaca atau tidak terkoneksi ke PLC.

\section{Penutup}

Berdasarkan hasil pengujian terhadap pembuatan alat Perancangan sistem Mounting Device berbasis PLC dengan menggunakan HMI, maka dapat disimpulkan bahwa PLC yang digunakan untuk mengontrol/mengaktifkan sensor yang berfungsi untuk membuka/memasang tutup kaleng telah bekerja dengan baik dan optimal.

Demikian juga untuk output seperti konveyor, motor DC, dan pneumatic yang terhubung dengan PLC telah bekerja dengan baik. Terutama untuk HMI yang sangat diperlukan dalam proses perancangan alat ini telah bekerja sesuai dengan kebutuhan dan berjalan dengan baik.. Hasil pengujian alat yang sudah dibuat telah diperoleh dari kinerja alat prototype otomasi sistem Mounting device ini.

\section{REFERENSI}

[1] Risfendra, Kontrol Otomasi Industri: Teori dan Praktek. Malang: CV IRDH, 2019.

[2] Risfendra, O. Candra, Syamsuarnis, and Firman, "Teaching Aid Development of Elecropneumatic Based Automation Course," in Advances in Social Science, Education and Humanities Research, 2019, vol. 299, no. Ictvet 2018, pp. 214-217.

[3] A. P. Dasril and Risfendra, "Perancangan Human Machine Interface untuk Sistem Otomasi Storage Berbasis PLC," JTEV (Jurnal Tek. Elektro dan Vokasional), vol. V, no. 1, pp. 1-6, 2019.

[4] H. Haryanto, "Perancangan HMI untuk Pengendalian Motor DC," J. SETRUM, vol. 1, no. 2, 2012.

[5] R. Faikar, Perancangan Sistem Antar Muka Berbasis HMI pada Mesin YCP. Semarang: Universitas Diponegoro, 2015.

[6] H. Berger, Automating with SIMATIC S7-300 inside TIA Portal. 2nd ed. Jerman: Erlangen, 2014.

[7] Datasheet, Reed Switch Band Mounting Style D-A73. SMC.

\section{Biodata Penulis}

Tito Ardiansyah, menyelesaikan studi DIV Teknik Elektro Industri pada Jurusan Teknik Elektro Fakultas Teknik Universitas Negeri Padang.

Risfendra, S.Pd, M.T, Ph.D, lahir di Riau, 13 Februari 1979. Sarjana Teknik Elektronika di Universitas Negeri Padang, lulus tahun 2004, S2 Teknik Sistem Pengaturan, ITS tahun 2008. S3 Shouten Taiwan University, of science and technology, Taiwan tahun 2017. Staf pengajar pada Jurusan Teknik Elektro FT UNP sejak tahun 2005 - sekarang. 